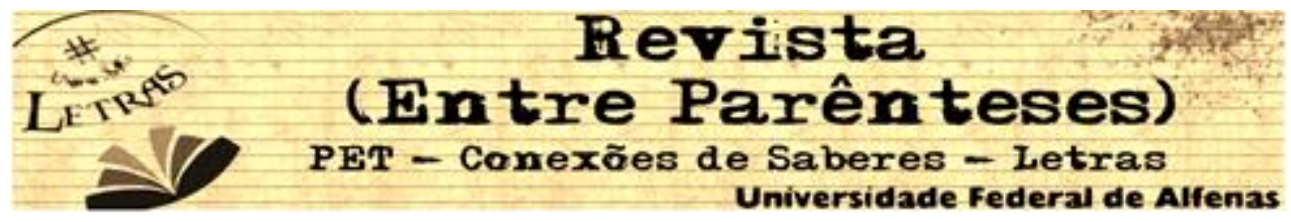

\title{
SINGULARIDADE E COERÇÃO NO RECORTE DAS VOZES: 0 GÊNERO REDAÇÃO DE VESTIBULAR EM ANÁLISE
}

\author{
Vanda Mari Trombetta ${ }^{1}$ \\ Universidade Federal da Fronteira do Sul (UFFS) \\ (vandamtt@hotmail.com)
}

\begin{abstract}
Resumo: Neste estudo, pretende-se investigar indícios que permitam refletir sobre duas questões: o gênero discursivo traz coerção às vozes recortadas do já-dito e em que medida o sujeito pode estabelecer possíveis singularidades a esse recorte? Concebe-se a partir da obra de Bakhtin e o Círculo que as atividades do sujeito estão condicionadas aos gêneros do discurso e a noção de singularidade está vinculada ao espaço histórico-social. É na corrente da enunciação - o dialogismo - que o sujeito organiza a escrita. O corpus é constituído por 40 redações de vestibulandos, do ano 2006 do vestibular da Fuvest, com o tema trabalho. Com base no paradigma indiciário, o estudo busca indícios nas redações que permitam caracterizar as coerções do gênero e a singularidade do sujeito pelas marcas construídas em seu diálogo com o já-dito. As análises apontam que o autor-criador sofre as coerções do gênero redação de vestibular, recortando vozes específicas de esferas mais valoradas pela própria constituição desse gênero, mas, também, afetado pelo momento histórico em que enuncia, recorta vozes marcadas pelas condições de seu tempo, de sua realidade.
\end{abstract}

Palavras-chave: singularidade; dialogismo; gênero discursivo.

\begin{abstract}
In this study, we intend to investigate indications that allow reflecting on two questions: does the discursive genre bring coercion to the juxtaposed voices of the already-said and to what extent can the subject establish possible singularities to this clipping? It is conceived from the work of Bakhtin and the Circle that the activities of the subject are conditioned to the genres of discourse and the notion of singularity is linked to the historical-social space. It is in the stream of enunciation - the dialogism - that the subject organizes the writing. The corpus is made up of 40 essays by the students of the 2006 Fuvest college entrance examination, with the theme work. Based on the Indiciary Paradigm, the study seeks indications in the essays that allow characterizing the coercion of the genre and the singularity of the subject by the marks constructed in their dialogue with the already-said. The analysis shows that the author-creator suffers from the constraints of the genre of vestibular writing, cutting specific voices of spheres more valued by the very constitution of this genre, but also affected by the historical moment in which it states, cut out voices marked by the conditions of his time, of their reality.
\end{abstract} Keywords: singularity; dialogism; discursive genre.

Resumen: Este estudio pretende investigar indicios que permitan reflexionar sobre dos cuestiones: ¿el género discursivo proporciona la coerción a las voces recortadas de lo ya-dicho? y ¿en qué medida el sujeto puede establecer posibles singularidades a tal recorte? Se concibe, a partir de la obra de Bakhtin y del Círculo, que las actividades del sujeto están condicionadas a los géneros del discurso y que la noción de singularidad está vinculada al espacio histórico-social. Es en la corriente de la enunciación o dialogismo - que o sujeto organiza la escritura. El corpus está constituido por 40 redacciones de candidatos al ingreso en la Universidade de São Paulo, del año 2006 (del proceso selectivo - vestibular

\footnotetext{
${ }^{1}$ Doutora em Letras pela Universidade de São Paulo, professora na Universidade Federal da Fronteira do Sul.
} 


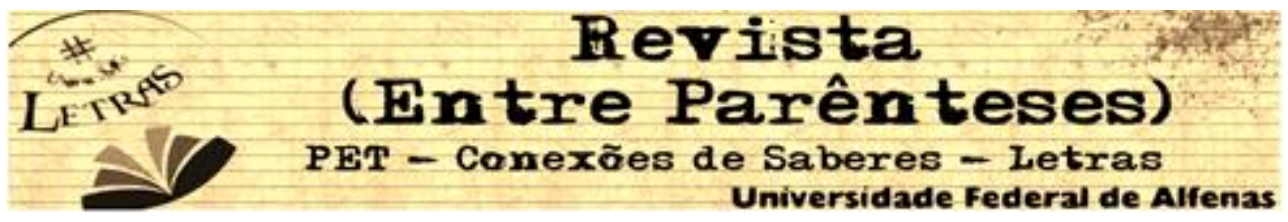

- de la Fuvest), con el tema trabajo. Teniendo como base el paradigma indiciario, el estudio busca indicios em las redacciones que permitan caracterizar las coerciones del género y la singularidad del sujeto por las marcas construidas en su diálogo con lo ya-dicho. los análisis apuntan para la idea de que el autor-creador sufre las coerciones del género redacción de vestibular, recortando voces específicas de esferas más valoradas por la propia constitución del género, pero, también, afectado por el momento histórico en que enuncia, recorta voces marcadas por las condiciones de su tiempo, de su realidad.

Palabras-clave: singularidad; dialogismo; género discursivo.

\section{Considerações iniciais}

A atividade do sujeito na linguagem foi objeto de reflexão na obra de Bakhtin e do Círculo. Dentre as importantes contribuições, assinalamos a ideia de que a singularidade não está particularmente em um sujeito, uma vez que sua constituição está vinculada ao histórico-social, construído a partir de e nas relações sociais. Não haveria uma essência que pré-determina sua constituição, dado que o sujeito se dá no próprio processo do existir, é a existência histórico-social que vai configurando-o.

Ao se conceber que o sujeito se constrói no processo do viver, implica pensá-lo constituído de uma dimensão histórica ${ }^{2}$, ou seja, o sujeito se configura enquanto sujeito precisamente em uma caminhada histórica, simultaneamente social, porque esse existir está referido também às atividades desempenhadas nas mais diversas esferas sociais. Existir que também está condicionado aos gêneros do discurso, nas palavras de Bakhtin (2007, p. 302), pois o "querer-dizer do locutor se realiza acima de tudo na escolha de um gênero do discurso". De modo que os gêneros organizam as comunicações, assim sendo, não são os sujeitos que optam no processo por esse ou aquele gênero: é a esfera social, junto à temática que possa ser discutida pelos parceiros, que balizam o dizer.

Pretende-se investigar, neste estudo, indícios que permitam refletir sobre as questões: o gênero discursivo traz coerção às vozes recortadas do já-dito e em que medida o sujeito pode estabelecer possíveis singularidades a esse recorte?

\footnotetext{
${ }^{2}$ A história "não é pensada como evolução cronológica: o que interessa não são as datas, mas os modos como os sentidos são produzidos e circulam" (ORLANDI, 1996, p.33).
} 


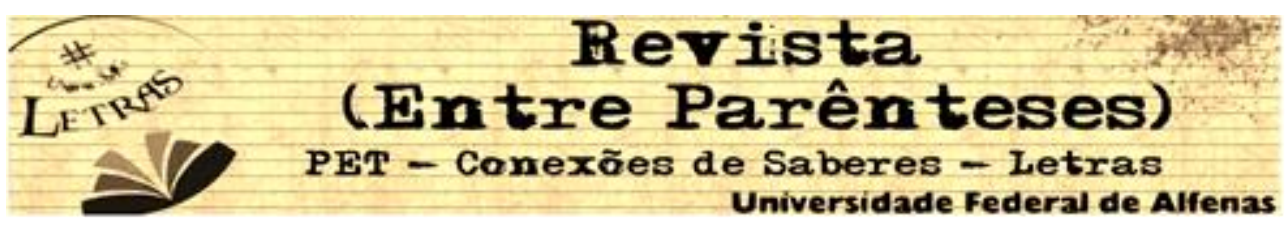

Inicialmente, são trabalhados os temas: sujeito, dialogismo, singularidade, autorcriador e, posteriormente, discutem-se as coerções do gênero discursivo, especificamente o gênero discursivo em análise, redação de vestibular. Na sequência, investigam-se, no corpus, indícios que permitam contribuir com a questão. $\mathrm{O}$ corpus em análise são redações do vestibular da Fuvest ${ }^{3} 2006$, sobre o tema "trabalho".

\section{1 - Sujeito, dialogismo e singularidade}

O sujeito é concebido na teoria bakhtiniana como um ser social-histórico, um sujeito cuja existência se concretiza na relação com o outro. É o conceito de "dialogismo" (BAKHTIN, 2010) - permanente diálogo entre os discursos que se configuram em uma sociedade - que estabelece uma ruptura tanto com a visão de sujeito fonte e de sujeito assujeitado. Não é um sujeito fonte, uma vez que se constrói na corrente de enunciados, na relação permanente com o outro; todavia, não é um sujeito assujeitado, pois atua também nessa corrente de enunciados.

Pensar que o dialogismo constitui todos os enunciados e os sujeitos é remeter a dois princípios. O primeiro concerne a não autonomia dos enunciados, uma vez que estão inevitavelmente atravessados por outros que já o antecederam, mas que também estão por vir. O segundo, a não autonomia do sujeito ao enunciar, pois também está atravessado, fundado pelo outro nos discursos que o antecederam, por vozes que condicionam sua enunciação. As vozes referem-se à consciência falante que se faz presente nos enunciados (BAKHTIN, 2010), ou seja, a cada enunciado proferido, emerge uma "multidão das vozes interiorizadas [...] são, assim, compósitos de vozes" (FARACO et al., 1998, p.167-168). "Cada voz possui sua cronotopia - sua raiz espaço-temporal - que a situa como única, e sua ideologia, que a identifica como entidade social" (BUBNOVA, 2011). A voz é uma ideia, especificamente uma postura ideológica. Os enunciados concebidos dessa maneira são "visões do mundo materializadas nas vozes" (BAKHTIN, 2010, p. 354).

3 Fundação Universitária para o Vestibular

\begin{tabular}{|c|c}
\hline Revista (Entre Parênteses) \\
Volume 6, Número 2, 2017 - ISSN 2238-4502
\end{tabular}




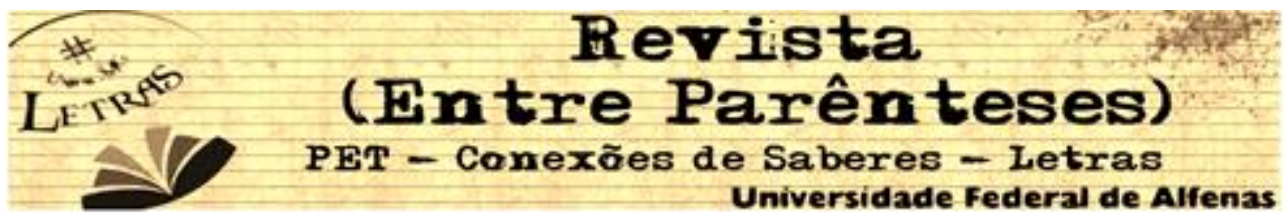

O sujeito concebido por Bakhtin configura e desenvolve sua experiência discursiva:

em uma interação constante e contínua com os enunciados individuais dos outros. Em certo sentido, essa experiência pode ser caracterizada como processo de assimilação - mais ou menos criador - das palavras do outro (e não das palavras da língua). Nosso discurso, isto é, todos os nossos enunciados (inclusive as obras criadas) é pleno de palavras dos outros, de um grau vário de alteridade ou de assimilabilidade, de um grau vário de aperceptibilidade e de relevância. Essas palavras dos outros trazem consigo a sua expressão, o seu tom valorativo que assimilamos, reelaboramos, e reacentuamos (2010, p. 294-295).

Nessa citação, é possível observar que são pelas palavras alheias de outros sujeitos que as nossas ganham significação no discurso. Também é possível ressaltar três formas de manifestação do dialogismo ${ }^{4}$. A primeira refere-se à afirmação de que o enunciado está "em uma interação constante e contínua com os enunciados individuais dos outros". Os enunciados formariam elos numa corrente da enunciação ininterrupta, à medida que um discurso remete a outros, um não existe sem o outro. Há um diálogo permanente entre enunciados, mas o sujeito não tem consciência de que está sempre retomando enunciados outros. Todo enunciado, "desde a curta réplica do diálogo familiar até as grandes obras verbo-ideológicas (literárias, cientificas e outras) existe, numa forma aberta ou velada, uma parte considerável de palavras significativas de outrem, transmitidas por um ou outro processo" (BAKHTIN, 2010b, p.153)

A segunda manifestação observa-se na referência de que todo enunciado "é pleno de palavras dos outros". Bakhtin/Voloschinov (2006) concebe duas tendências à reação da palavra de outrem: 1) o estilo linear cria "contornos exteriores

\footnotetext{
${ }^{4}$ Baseado na teoria de Bakhtin, Fiorin (2008) concebe que o dialogismo pode se manifestar de dois modos: constitutivo e composicional. O constitutivo "não se mostra no fio do discurso" (p.32). O composicional se mostra no discurso e divide em discurso objetivado (discurso alheio é abertamente citado e nitidamente separado do discurso citante) e discurso bivocal (internamente dialogizado, não há separação muito nítida do enunciado citante e do citado). Mas, reforça o autor "o dialogismo não é visto separadamente entre enunciados e entre o locutor e seu interlocutor. Na verdade, o interlocutor é sempre uma resposta, um enunciado e, por isso, todo dialogismo são relações de enunciados" (FIORIN, 2008, p.32).
} 


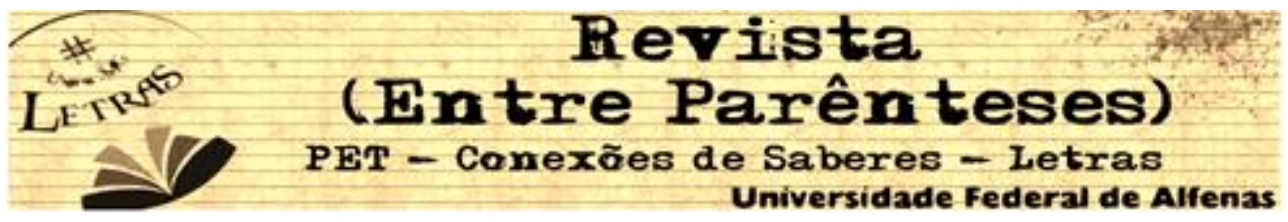

nítidos à volta do discurso citado" (p.151). Essa separação pode se manifestar pelo discurso direto, discurso indireto, uso das aspas, da negação; 2) o estilo pictórico atenua "os contornos exteriores nítidos da palavra de outrem" (p.152), pode apresentar os seguintes procedimentos: paródia, estilização, polêmica, discurso indireto livre. Nessa segunda manifestação, há uma demarcação mais aparente do sujeito sobre no enunciado, uma vez que escolhe formas mais ou menos visíveis para inserir a voz do outro.

$\mathrm{Na}$ terceira manifestação, pode-se considerar a ideia de reelaborar e reacentuar, é a subjetividade que se manifesta.

O enunciado nunca é simples reflexo ou expressão de algo que the preexistisse, fora dele, dado e pronto. $O$ enunciado sempre cria algo que, antes dele, nunca existira, algo novo e irreproduzível, [...] qualquer coisa se cria sempre a partir de uma coisa que é dada [...]. O dado se transfigura no criado (BAKHTIN, 2010, p. 348)

A partir do dado, as vozes criam o fundo necessário para a ascensão da voz do sujeito, é a singularidade que se manifesta reelaborando o já-dito, havendo produção de outros sentidos. O sujeito realiza escolhas dentre as alternativas que o social-histórico lhe oferece e intervém, imprimindo marcas: aquela ou outra direção para apresentar um tema, aquela ou outra palavra, aquela ou outra citação. Nessa relação com o já-dito, há reelaboração e transformação, o que resulta em mudança ao já-dito.

O já-dito reflete percepções de mundo, juízos e valores que se configuram e ganham apreciações no processo interativo com outras vozes nas quais o sujeito se apoia ou com as quais estabelece diferenças: "As palavras estão sempre carregadas de um conteúdo ou de um sentido ideológico ou vivencial", (BAKHTIN/VOLOSCHINOV, 2006, p.96, grifos do autor). Desse modo, o que é do sujeito é a forma como ele recebe, incorpora, organiza, valora ou não as vozes dos outros. É a partir de um sujeito que reflete e se posiciona que o "signo está sujeito aos critérios de avaliação ideológica (isto é: se é verdadeiro, falso, correto, justificado, bom, etc.)" (BAKHTIN/VOLOSCHINOV, 2006, p. 30).

Revista (Entre Parênteses)
Volume 6, Número 2, 2017 - ISSN 2238-4502




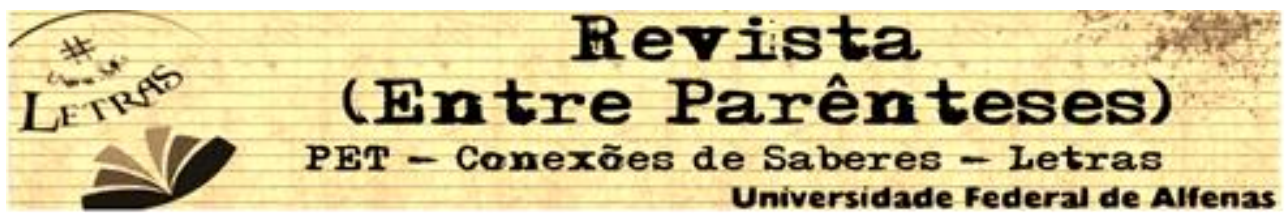

$\mathrm{Na}$ mesma perspectiva que o signo, as vozes poderão funcionar de diferentes maneiras para diferentes sujeitos, pois, ao serem incorporadas, podem sofrer alterações, uma vez que desde sua assimilação ou sua reestruturação, perpassam por valores morais, éticos, estéticos, religiosos, dentre outros. Para cada situação de enunciado, elabora-se uma resposta. Assim, não há uma assimilação igual para todas as manifestações. Não é igual, uma vez que ao "olharmos para nós mesmos com os olhos do outro, na vida sempre tornamos a voltar para nós mesmos, e o último acontecimento, espécie de resumo, realiza-se em nós nas categorias de nossa própria vida" (BAKHTIN, 2010, p. 14).

Nesse sentido, um enunciado sempre apresenta a marca da subjetividade de quem o produziu, pois há sempre um retorno a si mesmo, mas não no sentido de ser apenas expressão de um sujeito, pois:

Todo produto da ideologia leva consigo o selo da individualidade do seu ou dos seus criadores, mas esse próprio selo é tão social quanto todas as outras particularidades e signos distintos das manifestações ideológicas. Assim, todo signo, inclusive o da individualidade, é social (BAKHTIN, VOLOSCHINOV, 2006, p. 57).

Nenhum discurso é inteiramente de um sujeito, é um discurso constituído de vozes de outros sujeitos. O que é do sujeito é a forma de organizar, valorar ou não as vozes dos outros. Vozes estão presentes ancorando os enunciados e se reapresentando num novo tempo e espaço. Os enunciados constituem um diálogo permanente, inacabado, razão pela qual Bakhtin propõe pensar na natureza dialógica da linguagem: um diálogo inacabado.

\section{2- Autor-criador}

A singularidade em um enunciado é instaurada pelo autor-criador, um posicionamento do autor-pessoa ${ }^{5}$ (BAKHTIN, 2010, p.10). O autor-criador é uma

\footnotetext{
5 No texto "O autor e o herói na atividade estética", Bakhtin (2010) realiza uma distinção entre: autor-
} 


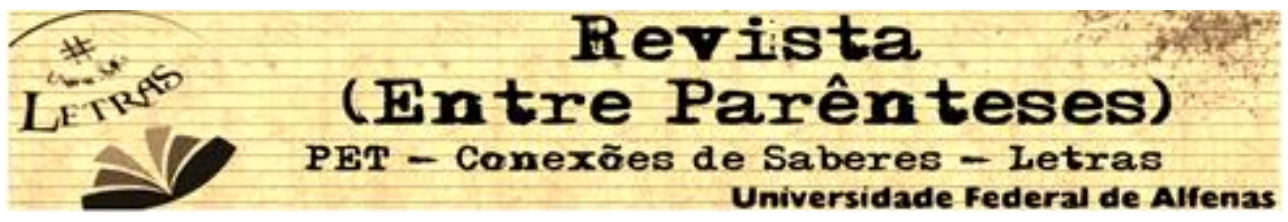

instância do discurso, é um sujeito instaurado no discurso e pelo discurso. É ele quem trabalha, segundo Bakhtin (1990), "axiologicamente as muitas faces da língua (a fônica, a sintática e a referencial), isto é, seleciona estas faces não da língua em si (gramática e dicionário), mas [...] da boca dos outros, ou seja, dos enunciados passados" (FARACO, 2011, p.23).

O autor-criador, um organizador das vozes do já-dito, conduz o diálogo de modo a fazer com que as vozes discutam, se posicionem, se contrariem, se afirmem. A condução desse diálogo, muitas vezes, é parcial, uma vez que o sujeito não tem o controle total das vozes que penetram na interação com o outro, que entram em discussão no momento do acontecimento, assim, o controle total é uma pretensão, pois o já-dito pode deixar de ser consciente ${ }^{6}$, uma vez que muitas vezes são as vozes que representam suas ideias e posicionamentos sobre o mundo e não ele que as representa.

Como também o acesso às vozes que o sujeito tem, são somente vozes de uma parte dos enunciados sobre um tema. $\mathrm{O}$ sujeito não tem acesso à memória de todos os enunciados, a constituição da sua memória discursiva, é parte de enunciados que já foram proferidos em outras épocas, em outras situações interacionais, nas quais o sujeito conscientemente e inconscientemente toma como base para formular seu discurso. Enunciados anteriores estão na memória discursiva do sujeito, mas o

‘já experimentado' (...) não é simplesmente a memória do já vivido empírico. Muitas vivências simbólicas escapam à remissão a uma ocorrência linguística particular, mas podem ser pensadas, por exemplo, como feixes de enunciados que, de idades e de espaços díspares, se cruzam e atuam, por recorrência ou apagamento, sobre a dispersão das lembranças para compor uma memória (CORRÊA, 2008, p.262).

pessoa e o autor-criador. O autor-pessoa é a pessoa que escreve. Sujeito físico, real, portanto sempre em processo de formação, por essa razão que é inacabado, está em constante processo. E o autorcriador é um sujeito do discurso, da linguagem. $O$ autor-criador é quem dá forma ao conteúdo tematizado, é uma segunda voz que não é mais do autor-pessoa, embora seja proveniente deste.

6 Remetemo-nos à questão do inconsciente, pois segundo Freud não somos senhores nem de nós mesmos, pois a consciência é a menor parte e a mais fraca de nossa vida psíquica. (CHAUÍ, 2003, p.168). 


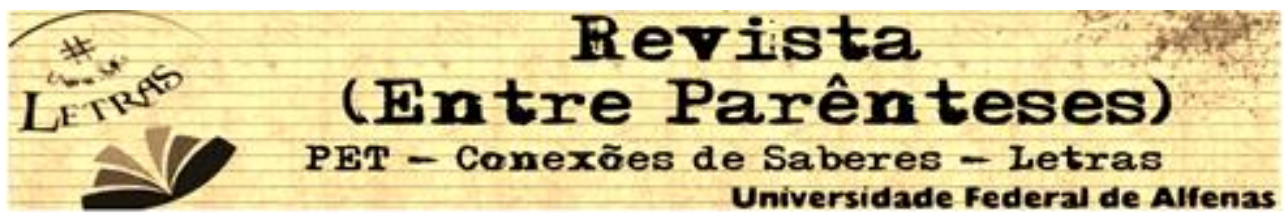

O já-dito funciona não só como recuperação de um já-enunciado, mas como condição e pré-requisito para o surgimento do novo. É o movimento do autor-criador realizando incursões sobre o dizer do outro para organizar o seu dizer, que os discursos ganhariam outros sentidos.

Se estabelecermos hipóteses de qual a razão do autor-criador acessar um e não outro enunciado, uma possível resposta é o que abordamos no parágrafo anterior - o acesso a somente parte do já-dito. Mas, outra justificativa que é significativa para este estudo, é a de que os enunciados têm diferentes matizes, e o trazer esse ou aquele enunciado está relacionado à relação emotivo-valorativa do autor-criador, pois

expressar uma atitude emotivo-valorativa ante a realidade não se refere a nenhuma realidade determinada; apenas um locutor pode estabelecer [...] um juízo de valor a respeito da realidade, [...]. As palavras [...] estão a serviço de qualquer locutor e de qualquer juízo de valor, que podem mesmo ser totalmente diferentes, até mesmo contrários (BAKHTIN, 2010, p. 309).

Ao significar um tema, apreende-se também seu valor, é a partir da relação emotivo-valorativa que se intui também se o objeto é verdadeiro ou falso, belo ou feio, bom ou ruim, justo ou injusto. A significação está, então, atrelada à relação que o autor-criador estabelece com o objeto e os aspectos de valoração envolvem propriedades que o caracterizam, elaborando a linguagem, singularizando-se a si e ao enunciado construído.

O autor-criador ao compor "aspectos de um plano de valores para outro plano de valores, organizando um novo mundo" (FARACO, 2005. p. 39), constrói os enunciados, traz, então, elementos que já estão inseridos em certo plano axiológico e, analisando sob outro olhar, os reordena, construindo outro sistema valorativo. A relação valorativa está mediada pelo estabelecimento de relações entre o que foi dito do tema e sobre o próprio tema no momento do enunciado.

Assim, no corpus em análise, nas redações de vestibular, o autor-criador

\begin{tabular}{l}
\hline Revista (Entre Parênteses) \\
Volume 6, Número 2, 2017 - ISSN 2238-4502
\end{tabular}




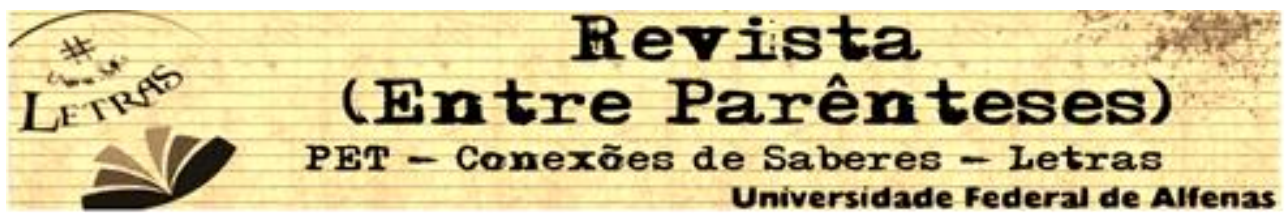

operará sobre determinados planos axiológicos - apreciações, juízos de valor - a fim de desenvolver a sua proposta de escrita. $\mathrm{O}$ autor-criador poderá retirar elementos da coletânea que correspondem a um plano axiológico ou também poderá recortar elementos do seu mundo, outro plano axiológico. Para esses recortes, o autor-criador pode, por exemplo, se valer do uso do discurso de outrem (da coletânea ou fora da coletânea) para criar o seu, mantendo as vozes de maneira implícita, inseparável do seu enunciado, configurando, por exemplo, um elemento do discurso pictórico, ou optar por manter as vozes de maneira explícita, configurando um discurso mais linear. Pode, ainda, optar pela construção de um novo discurso, logo, o enunciado desse outrem receberá outro olhar, que poderá construir outro contexto de relações valorativas.

$\mathrm{Na}$ atividade do autor-criador, segundo Albani (2000), pode ocorrer fenômenos de deslocamento, substituição, acréscimo ou subtração de elementos, os quais visam à produção de efeitos de sentido que têm por objetivo criar um novo enunciado. As retomadas que o autor-criador fará criam novas possibilidades quando confrontadas com o que já foi exposto, ou seja, entre o criado e o dado, constituindo como uma atividade discursiva em que a produção de sentidos se processa por meio de um novo dizer atravessado por outras vozes.

Assim, se aceita como pressuposto para as análises, a ideia de que: I) o jádito é visto constituindo à linguagem, o discurso e não como simples retomada de um já falado/escrito, há sempre re-significações; ii) a singularidade está vinculada à situação de enunciação e, como assevera Bakhtin (2010), está indissoluvelmente ligada ao gênero do discurso.

O autor-criador enuncia pelo princípio constitutivo da linguagem, o dialogismo, um conjunto de saberes, já ditos, que constituem o que se diz, pelo viés valorativo a esse ou aquele discurso. Todo enunciado está condicionado por enunciados anteriores, o já-dito se apresenta, então, como indispensável para a realização desses, pois quando o autor-criador enuncia, há sempre algo que se mantém, retorna aos mesmos espaços do dizer, ao dialogismo. Há, portanto, atuação do autor-criador, pois há espaços de ação que permitem dizer de certo modo e não 


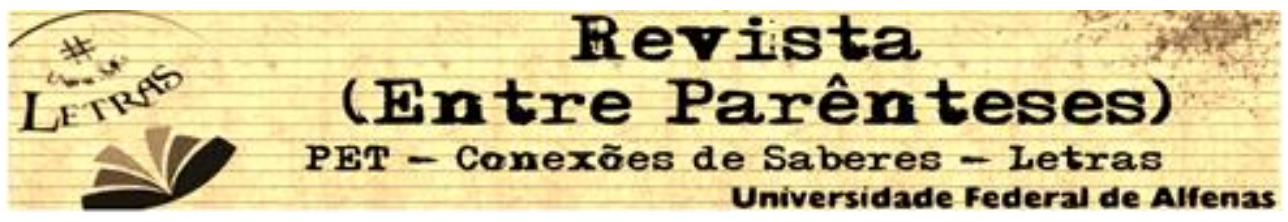

de outro, e, nesses espaços, sobressaem-se traços de sua singularidade.

\section{3 - Gênero discursivo e suas coerções}

O gênero constitui a linguagem de tal modo que Bakhtin concebe que "Aprendemos a moldar nossa fala às normas do gênero e, ao ouvir a fala do outro, sabemos de imediato [...] pressentir-Ihe o gênero [...], prever-Ihe o fim, ou seja, desde o início, somos sensíveis ao todo discursivo" (BAKHTIN, 2010, p.302). O que significa dizer que esse aprendizado é intrínseco às relações de interação, à medida que nos relacionamos socialmente, eis que, desde nosso nascimento ${ }^{7}$, vamos assimilando formas do gênero.

Inseridos numa esfera social, os gêneros discursivos interpelam o sujeito. Tem-se, então, a primeira coerção; a esfera na qual o gênero acontece determina a forma do gênero. O autor-criador enuncia condicionado às "formas típicas de estruturação do gênero do acabamento" (BAKHTIN, 2010, p. 299). Os gêneros "não deixam de ter um valor normativo: eles lhe são dados, não é ele que os cria" (p.305).

Os três elementos caracterizadores do gênero - "conteúdo temático, estrutura composicional, estilo" (BAKHTIN, 2010, p.284) - carregam também as coerções da esfera. Contextualizados na esfera, os três elementos orientam desde os recortes do tema, as representações dos interlocutores, o modo como as ideias devem estar dispostas no gênero, inclusive as formas da língua. Conceber que o centro organizador do gênero é o espaço social significa dizer que é o exterior que exerce coerção para o gênero.

Assim, a estabilidade é observada na regularidade dos três elementos que permite que sejam, inclusive, reconhecidos em determinados gêneros e que se operem com certas marcas sócio-históricas. O espaço social submete o gênero a

\footnotetext{
7 O segundo nascimento que Bakhtin (2012, p. 11) concebe é o "social". "Só essa localização social e histórica [...] o torna real e lhe determina o conteúdo da criação da vida e da cultura”. Com essa afirmação o autor se contrapõe às concepções que explicam as ações humanas pelo biológico pois, para ele, nem a biologia encontrará solução definitiva sem que se leve em conta o espaço social em que o homem vive.
}

Revista (Entre Parênteses)
Volume 6, Número 2, 2017 - ISSN 2238-4502




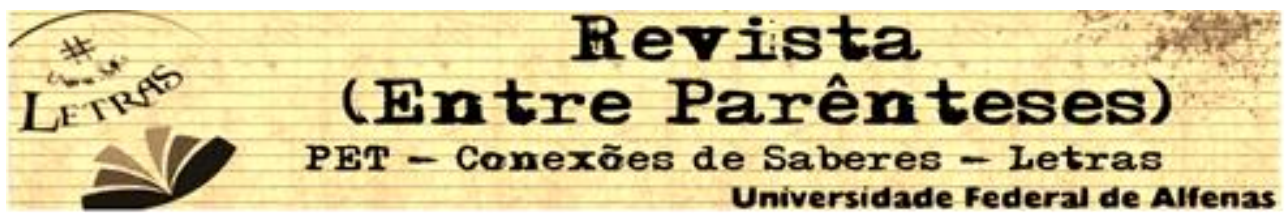

certas regularidades. Desse modo, em dado gênero, podem-se notar traços em comum que permitem, inclusive, classificar a que objetivam: informar, persuadir, contar, dentre outras intenções possíveis; como também, observar certas marcas discursivas que se repetem. Elementos que acabam por condicionar as escolhas do autor-criador que perpetuam o uso do gênero mais adequado.

Para além das regularidades que os caracterizam e que permitem serem reconhecidos, os gêneros são também suscetíveis a mudanças, pois suas formas são "mais maleáveis, mais plásticas e mais livres" (BAKHTIN, 2010, p.303) e permitem que o sujeito aja sobre eles. Os gêneros apresentam então uma estabilidade relativa, pois a "palavra, como fenômeno ideológico por excelência, está em evolução constante, reflete fielmente todas as mudanças e alterações sociais. O destino da palavra é o da sociedade que fala." (BAKHTIN/VOLOSHINOV, 2006, p. 180).

É o autor-criador em um dado gênero que atende tanto as coerções, como também, a partir dele, faz escolhas dentre as possibilidades que o gênero lhe possibilita. As escolhas são sempre sócio-históricas, nunca individuais.

\section{1 - Gênero discursivo redação de vestibular e as coerções}

A redação de vestibular é concebida, aqui, enquanto gênero discursivo ${ }^{8}$, uma vez que a escrita é concebida como processo, que reflete as práticas sociais dos vestibulandos. Também, a leitura e as análises dessas redações não se centram somente na estrutura do enunciado, mas principalmente no que o constitui: conteúdo temático, estrutura composicional e estilo (BAKHTIN, 2010). Logo, pensar a redação de vestibular como um gênero discursivo permite que se trabalhe "em função de sua produtividade no reconhecimento do processo de constituição do texto." (CORRÊA,

\footnotetext{
${ }^{8}$ Corrêa (2011) aponta quatro situações para defender que a redação de vestibular é um gênero discursivo: 1) há uma interação social específica (avaliado/avaliador) válida para todos esses textos; 2) há um comportamento verbal semelhante mesmo na produção de tipos diferentes; 3) as escolhas temáticas são filtradas por um interesse educacional (temas relevantes da atualidade); e 4) as soluções estilísticas estão ligadas ao diálogo com a instituição avaliadora. "Conjunto dessas restrições configura um gênero do discurso que vem sendo especificado pelo predomínio de certos tipos de texto, como, por exemplo, o dissertativo e o narrativo" (CORREAA, 2011, p.637).
} 


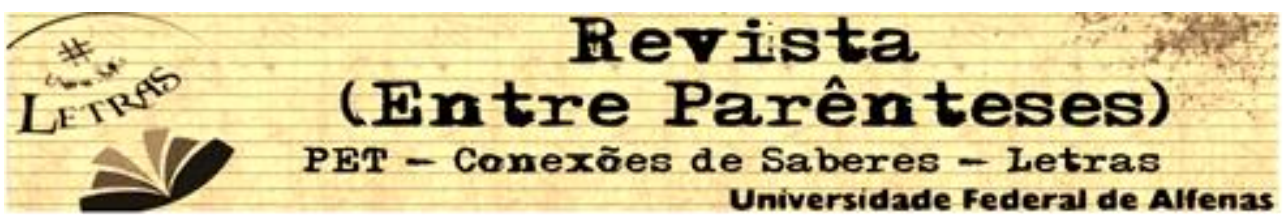

2011, p. 638). Mas, também, tratá-la como gênero é pensar desde as coerções do gênero proposto, inclusive da instituição que elabora a prova, da banca corretora, da proposta de construção do gênero, dos excertos da coletânea, do tema.

No gênero em análise, pode-se pensar em outras formas de coerções, como por exemplo, do acontecimento discursivo, "o ponto de encontro entre uma atualidade e uma memória" (PÊCHEUX, 1997, p.17). Isto é, se o exame de vestibular é considerado um acontecimento discursivo, há um encontro de uma memória discursiva: enunciados que passaram por esse vestibulando ao longo da vida sobre o tema, sobre o próprio exame, a língua, o texto, o discurso; e uma atualidade: a instituição em que o exame de vestibular é realizado, a proposta da redação de vestibular estar construída de certo modo, os excertos específicos que formam a coletânea.

Mesmo reconhecendo que esse conjunto de coerções possa condicionar a grande incidência de redações típicas, que seguem modelos muitas vezes ensinados e treinados nas instituições escolares, acredita-se que há, mesmo assim, um trabalho do sujeito na linguagem. Nesse sentido, o vestibulando (autor-criador) pode marcar sua singularidade reagindo, pois, por exemplo, às possibilidades dos enunciados apresentados pela prova. E o faz, aceitando-os, modificando-os, assimilando certos elementos neles existentes, ou transformando-os em outros enunciados. São essas possibilidades que orientam a escrita do gênero, mesmo considerando as coerções anteriormente apontadas.

\section{4 - Corpus, metodologia e análise}

O corpus é constituído por $40^{9}$ redações de vestibulandos, do ano 2006 do vestibular da Fuvest ${ }^{10}$, com o tema trabalho. Da prova, fazia parte uma coletânea e uma instrução. Da instrução, constavam três orientações: (1) ler três textos da

\footnotetext{
${ }^{9} \mathrm{O}$ corpus totaliza um conjunto de 270 textos. A seleção das redações foi feita de modo aleatório pela própria FUVEST, dentre os candidatos ao curso de Letras.

${ }^{10}$ Fundação Universitária para o Vestibular
}

\begin{tabular}{|c|c}
\hline Revista (Entre Parênteses) \\
Volume 6, Número 2, 2017 - ISSN 2238-4502
\end{tabular}




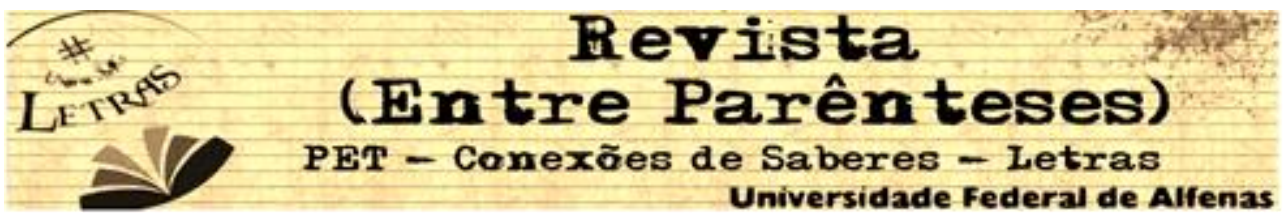

coletânea que apresentam diferentes visões de trabalho; (2) relacionar esses três textos e com base nas ideias neles contidas, além de outras que julgar relevantes; (3) redigir uma dissertação em prosa.

Reafirmando que a relação valorativa está mediada pelo estabelecimento de relações entre o que foi dito (a coletânea), o que foi percebido (da coletânea e do próprio tema ao longo da vida) e o próprio objeto do escrever (o tema trabalho), destaca-se que são essas relações valorativas, nas condições de um exame de vestibular, que fazem com que se tenha um percurso de construção e não outro.

Com base no paradigma indiciário (GINZBURG, 1989), o estudo proposto busca indícios deixados nas redações que permitam caracterizar as coerções e a singularidade no gênero pelas marcas construídas em sua dialogia com o já-dito. Encontrar indícios significa encontrar "zonas privilegiadas" (GINZBURG, 1989) de interpretação de uma realidade que não se mostra facilmente ao pesquisador. Ao adotar o paradigma indiciário, é possível recuperar fenômenos que influenciam a construção dos indícios materializados, concomitantemente, no que há de específico da situação enunciativa e elementos estabilizados nas e pelas interações ao longo da história. Considerando, então, que pistas estão circunscritas em textos, procura-se, a partir de hipóteses, interpretar e identificar marcas da relação do sujeito com 0 enunciado.

Para efeito de análise, analisa-se o já-dito a partir das diferentes esferas sociais as quais são acessadas para construir o gênero. Ao considerar as vozes, procura-se defender a hipótese de que o gênero, ao mesmo tempo em que apresenta coerções para o autor-criador selecionar vozes específicas de determinadas esferas, também recebe a singularidade do autor-criador, que traz vozes recortadas de vozes de outras esferas. Para evidenciar a coerção e singularidade, apontam-se exemplos ilustrativos das esferas valoradas.

A coerção é exemplificada pelo exemplo 1:

$\mathrm{Na}$ era pré-histórica a necessidade de trabalhar era de ordem lógica e prática. (...) Na Idade média houve uma grande ampliação

Revista (Entre Parênteses)
Volume 6, Número 2, 2017 - ISSN 2238-4502




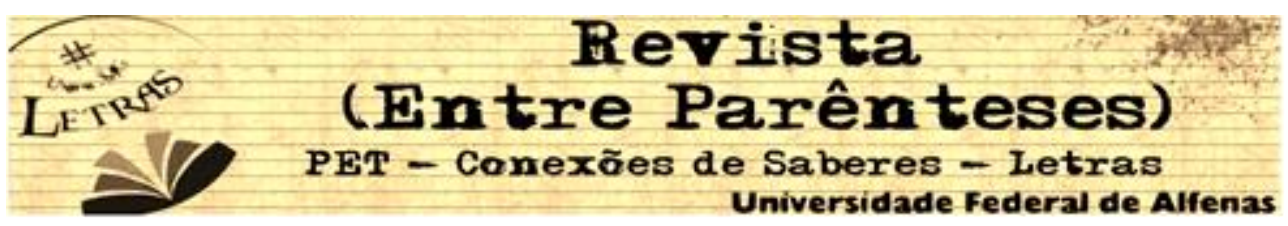

nas modalidades de trabalho, (...) Foi com o surgimento do protestantismo e com sua filosofia,(...) que paulatinamente o trabalho alcançou todas as classes sociais. (...) trabalho é uma dádiva divina (...). A sociedade moderna vive um dilema pois 0 capitalismo exige altos lucros, o que justifica a crescente mecanização da mão de obra, em contrapartida, a população se dilacera por uma vaga de emprego.

É possível notar que a argumentação é construída a partir das vozes que dialogam com a esfera escolar, vozes marcadas por argumentos-exemplos de fatos históricos - pré-histórica, Idade média, protestantismo, capitalismo - que sinalizam para a construção de que o conceito de trabalho se modifica de acordo com o período histórico.

A singularidade é exemplificada pelo exemplo 2:

A sociedade e o homem vive $[\mathrm{m}]^{11}$ para o trabalho. Sua vida é voltada para isso: A formação do indivíduo; A posição social e o Status; trabalha-se para viver e, assim, continuar trabalhando. Quantas vezes eu ouvi, quando criança a pergunta: "O que você vai ser quando crescer?" e era sempre no sentido profissional. Não adiantava eu responder queria ser grande. É a Super-valorização do trabalho.

O momento histórico que o escrevente vivencia, a escolha de um curso para prestar o vestibular, o conduzem a considerar a escolha profissional, como indicativo do trabalho constituindo sua vida. Esse momento histórico passa a integrar o recorte das vozes, os dois argumentos pelo exemplo - a pergunta O que você vai ser quando crescer? e a resposta, queria ser grande - especificam recortes de esfera familiar. A voz da esfera familiar indicia a singularidade do autor-criador, expressando o valor dado ao trabalho, não só permeando a vida do homem, como a supervalorização, pois, desde a infância presentes questionamentos sobre ser profissional são propostos.

\section{5 - Análises}

\footnotetext{
11 Os colchetes indicam acréscimos à redação, mas somente serão realizados quando dificultarem a compreensão. Outras intervenções, como alteração de acentos, ortografia não serão realizadas.
} 


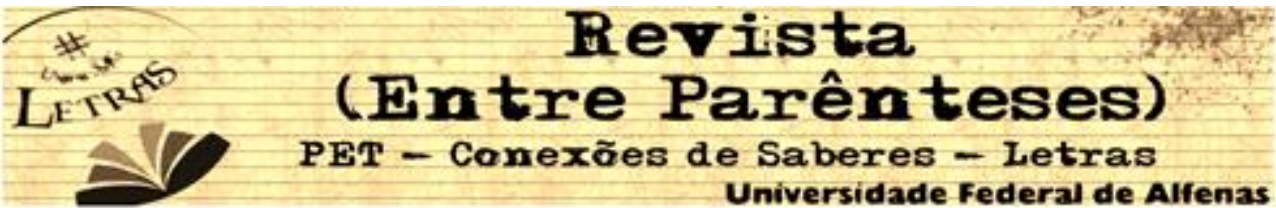

Entre outros exemplos de excertos que evidenciam a inserção do autorcriador em esferas específicas, atendendo a coerção do gênero, pode citar:

Exemplo 3- Um quadro do Portinari, um poema de Drummond ou uma música de Bach são trabalhos diferentes mas com uma característica fundamental: constituem-se um modo de expressão.

Exemplo 4- $O$ trabalhador está cada vez mais se escravizando. Trabalho e arte são coisas totalmente distintas para muitos. Michelangelo não é visto como um trabalhador e sim um artista que gerava apenas obras e não a tão esperada renda, quando deveria ser lembrado como alguém que fez aquilo que acreditava e achava certo, expressando suas ideias.

Exemplo 5 - A relação entre o homem e o trabalho sempre levantou questões provocativas e sempre teve um caráter atribulado. Essa questão chegou mesmo a ser a força motriz que impulsionava os pais do pensamento econômico, com Karl Marx, Keynes e outros (...).

Nos três exemplos acima, o autor-criador atende as coerções para o gênero, recortando vozes de esferas esperadas. No excerto 3, a esfera que valora o trabalho de arte é acionada para defender a argumentação que o trabalho é modo de expressão, os argumentos-exemplos são reconhecidos pela esfera escolar como pela própria da coletânea que já apresentava uma valoração para a voz do trabalho de arte: Um quadro do Portinari, um poema de Drummond ou uma música de Bach são trabalhos. No exemplo 4, a esfera acionada é a que considera que o trabalhador está cada vez mais se escravizando, o argumento-exemplo reporta-se a coletânea: Michelangelo não é visto como um trabalhador e sim um artista que gerava apenas obras e não a tão esperada renda, quando deveria ser lembrado como alguém que fez aquilo que acreditava e achava certo, expressando suas ideias. Para sustentar que a relação entre o homem e o trabalho sempre levantou questões provocativas $e$ sempre teve um caráter atribulado, o autor-criador da redação exemplo 5 traz o argumento de autoridade - os pais do pensamento econômico, com Karl Marx, Keynes e outros - amparado pela voz da esfera escolar.

Apresentam-se exemplos de excertos que evidenciam a singularidade do

Revista (Entre Parênteses)
Volume 6, Número 2, 2017 - ISSN 2238-4502




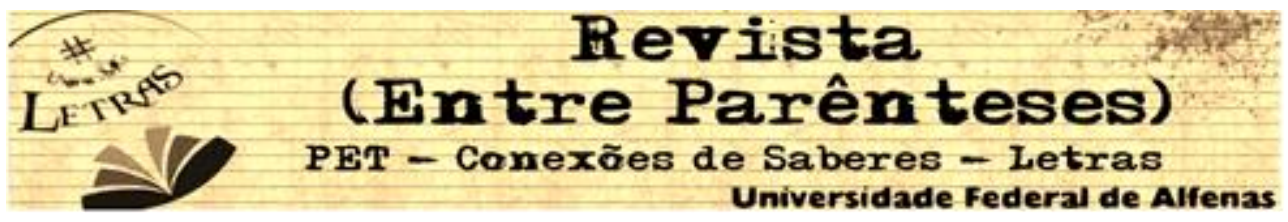

momento histórico do autor-criador.

Exemplo 6- Hoje em dia, o que se vê na busca do trabalho é a procura contínua pela garantia e pela estabilidade sem os quais se é excluído da sociedade de consumo em que vivemos. Nesse contexto, vocação e paixão são termos caídos em desuso. Certas profissões, como as carreiras artísticas, são vistas hoje com receio e preconceito, diante da possibilidade de fracasso.

Exemplo 7- E está cada dia mais difícil ingressar no mercado de trabalho. Precisamos melhorar a qualidade de ensino e aumentar a quantidade de empregos para todos que tenham oportunidade de mudar de vida para melhor.

Exemplo 8- O trabalho não é visto como uma atividade prazerosa, nem artística e sim algo "pesado" que faz recém formados calcularem desesperadamente quando vão poder se aposentar.

Exemplo 9- Um lamento ao pensar acerca do que será do amanhã, quando estiver já com certa idade incapaz de exercer a minha condição de existência, atualmente, o que me une com a sociedade: o trabalho.

Nesses exemplos, podemos ressaltar que embora o autor-criador estivesse sujeito às pressões do gênero, mesmo assim estabelece recortes que expressam suas inquietações em relação ao tema "trabalho". Nota-se uma interlocução maior com o momento histórico que o escrevente vivencia do que, por exemplo, uma das coerções do gênero redação de vestibular, as vozes pensadas para seu interlocutor (o leitor, a banca).

Em exemplo 6, a argumentação explora a relação trabalho e escolha profissional, o autor-criador expressa suas crenças baseadas em vozes que podem ser oriundas da esfera familiar ou do mercado que propagam que a procura contínua pela garantia e pela estabilidade (...) Nesse contexto, vocação e paixão são termos caídos em desuso. Certas profissões, como as carreiras artísticas, são vistas hoje com receio e preconceito, diante da possibilidade de fracasso.

A voz do mercado é trazida no exemplo 7 para argumentar sobre a razão para melhorar a qualidade de ensino, pois está cada dia mais difícil ingressar no 


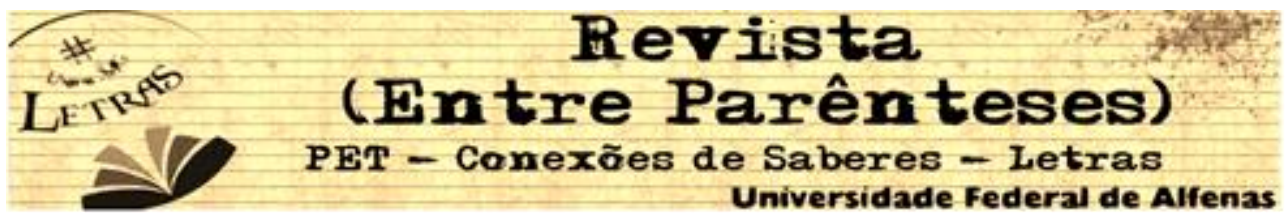

mercado de trabalho.

Em exemplo 8, há um questionamento sobre qual o sentido da vida sem trabalho, pois, segundo o autor-criador, o que me une com a sociedade é o trabalho e quando estiver com certa idade incapaz de exercer a minha condição de existência. É interessante aqui apontar o uso do pronome possessivo minha: há inserção de uma voz que se manifesta preocupada: o que fazer na aposentadoria? No exemplo 8, trabalho é visto como obrigação, poucos trabalham com a atividade que gostariam de executar, [...] não sobrando tempo para a família, o lazer e para a religiosidade. A voz, nesse excerto, está preocupada com a satisfação ao trabalhar e denuncia a ausência de tempo para outras atividades na vida.

No exemplo da redação 9, novamente ao trabalho é atribuído à qualificação "pesado", as aspas intensificam negativamente o substantivo. E, novamente aparece a preocupação com aposentadoria: faz recém formados calcularem desesperadamente quando vão poder aposentar. Podemos observar que as vozes no exemplo 8 trazem argumentos da falta de lazer na vida do trabalhador e a preocupação com a aposentadoria, mostrando-se atento ao trabalho na sociedade capitalista, deixa entrever um posicionamento crítico.

\section{Considerações finais}

Mediante a análise dos exemplos de excertos extraídos das redações, buscou-se refletir sobre a coerção e a singularidade no recorte as vozes no gênero discursivo redação de vestibular. Retiram-se ao menos dois indicativos de reflexão a partir das análises.

No primeiro conjunto, o autor-criador sofre as coerções do gênero redação de vestibular e recorta vozes específicas de esferas mais valoradas pela própria constituição do gênero: vozes da história, da sociologia, da arte na perspectiva da esfera escolar; vozes de crítica ao tratamento do trabalhador, oriundas de determinadas esferas, como de crítica ao capitalismo. As vozes demonstram que o autor-criador se adéqua à especificidade do gênero, recortando vozes já esperadas. 


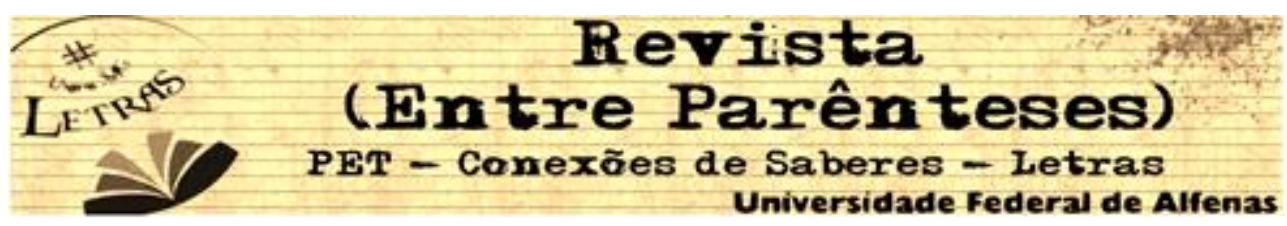

Em condições como de prova de vestibular, a tendência é maior estabilidade ainda dos gêneros, pois há uma regulação do que e como dizer na interação.

No segundo conjunto, houve manifestações que indicam "apreciação social" (BAKHTIN, 1995, p.135) bastante singular. O autor-criador, marcado pelas condições de seu tempo, de sua realidade, expõe marcas recorrentes nos excertos: trabalho e escola profissional, trabalho e escola, trabalho e seus significados, trabalho e lazer e aposentadoria. Posição de um autor-criador que representa uma posição do autor-pessoa afetado pelo momento histórico em que enuncia recorta vozes do já-dito; em hipótese, vozes dos pais, de professores, da mídia, do mercado ecoam.

Desse modo, o sujeito, na posição de autor-criador, vai se constituindo também pela escrita de um gênero bastante coercitivo com o de vestibular, e é pela constituição histórico-social que o gênero interpela, condicionando os recortes a determinadas vozes, mas é o próprio condicionamento do momento em que vive que traz ao gênero vozes que expõe sua singularidade.

A ideia de singularidade é relativa, pois traz um caráter social, não está em um único indivíduo. Nas considerações levantadas, procurou-se mostrar que, para além das relações de coerção, podem-se encontrar indícios de singularidade ao levarse em consideração que o autor-criador pode ser caracterizado pela maneira como organiza, segundo sua valoração, os já-ditos. Consequentemente, o gênero impõe coerções, mas também acaba sendo interpelado pela singularidade do autor-criador.

\section{Referências}

BAKHTIN, M.; VOLOSCHINOV, V. N. Marxismo e filosofia da linguagem. 12ª Ed. São Paulo: HUCITEC, 2006.

BAKTIN, M. Os gêneros do discurso. In. Estética da Criação Verbal. 5. Ed. São Paulo: Martins Fontes, 2010. p. 261-306.

O problema do texto. In. Estética da criação verbal. São Paulo: Martins Fontes, 2010, p. 327-358.

Observações sobre as epistemologias das ciências humanas. In. Estética da

Revista (Entre Parênteses)

Volume 6, Número 2, 2017 - ISSN 2238-4502 


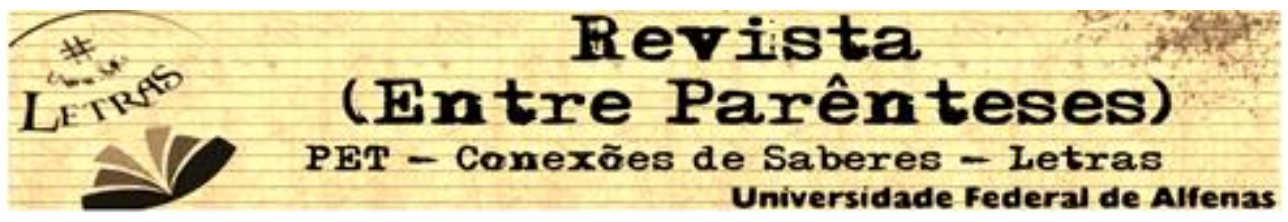

criação verbal. São Paulo: Martins Fontes, 2010, p. 399-414.

. O freudismo: um esboço crítico. São Paulo: Perspectiva, 2012.

Questões de literatura e de estética: a teoria do romance. São Paulo: Hucitec, 2010b.

BUBNOVA, T. Voz, sentido e diálogo em Bakhtin. Bakhtiniana. São Paulo, 6 (1): 268280, Ago./Dez. 2011. Disponível em: <<http://www.scielo.br/pdf/bak/v6n1/v6n1a16.pdf >> Acesso em novembro de 2017.

CORRÊA, M. L. G. Encontros entre prática e pesquisa de ensino: Oralidade e letramento no ensino da escrita. Perspectiva (UFSC), v. 1, p. 625-648, 2011.

. O estatuto da linguística aplicada no campo das ciências da linguagem e o ensino da escrita. Revista da ABRALIN, v. 7, n. 2, p. 243-271, jul./dez. 2008.

CHAUÍ, M. C. Convite à filosofia. São Paulo: Ática, 2003.

FARACO, C. A. Aspectos do pensamento estético de Bakhtin e seus pares. Letras de Hoje. Porto Alegre, v. 46, n. 1, p. 21-26, jan./mar. 2011.

Autor e autoria. In: BRAIT, Beth (org.). Bakhtin: conceitos-chave. São Paulo: Contexto, 2005, p. 37-60.

et al. O falante: que bicho é esse, afinal? Letras. Curitiba, n. 49. Editora da UFPR. 1998, p. 161-170.

FIORIN. J. L. Introdução ao pensamento de Bakhtin. São Paulo: Ática, 2008.

ORLANDI, E. P. Interpretação: autoria, leitura e efeitos do trabalho simbólico. Petropólis: Vozes, 1996.

PÊCHEUX, M. O discurso: estrutura ou acontecimento. Campinas: Pontes, 1997.

Recebido em 28/11/2017 Aceito em 12/01/2018

\begin{tabular}{l}
\hline Revista (Entre Parênteses) \\
Volume 6, Número 2, 2017 - ISSN 2238-4502
\end{tabular}

